\title{
Canadian health care professionals' knowledge, attitudes and perceptions of nutritional genomics
}

\author{
Mark Weir ${ }^{1}$, Karine Morin ${ }^{1}$, Nola Ries ${ }^{2}$ and David Castle ${ }^{3 *}$ \\ ${ }^{1}$ Department of Philosophy, University of Ottawa, Ottawa, ON, Canada \\ ${ }^{2}$ University of Victoria, Victoria, BC, Canada \\ ${ }^{3}$ Faculty of Arts and Faculty of Law, University of Ottawa, Ottawa, ON, Canada \\ (Received 24 November 2009 - Revised 18 March 2010 - Accepted 19 April 2010 - First published online 16 June 2010)
}

Nutritional genomics has reached the public through applications of the Human Genome Project offered direct to consumers (DTC). The ability to pursue nutrigenetic testing without the involvement of a health care professional has received considerable attention from academic and policy commentators. To better understand the knowledge and attitudes of Canadian health care professionals regarding nutritional genomics and nutrigenetic testing, qualitative research in the form of focus group discussions was undertaken. Four key themes emerged: (1) concerns over DTC testing; (2) lack of health care professional competency; (3) genetic scepticism and inevitability; (4) expectation of regulation. Together, they indicate that health care professionals have little knowledge about nutritional genomics and hold contradictory attitudes towards genomics in general, and to nutritional genomics in particular. Respondents argue in favour of a delivery model where health care professionals act as intermediaries. They are also aware of their lack of competency to provide such services. To ensure greater public protection, respondents cite the importance of more stringent regulatory oversight of DTC genetic testing. Whether such an approach is necessary to address the various ethical and social issues raised by nutrigenetic testing remains an open debate.

Health care professionals: Nutritional genomics: Direct-to-consumer genetic tests: Nutrigenetics

Evolving as one of the first applications of the knowledge generated from the Human Genome Project to reach the public, nutritional genomics involves the study of genomewide influence of nutrition, including how certain genes affect the risk of diet-related diseases ${ }^{(1,2)}$. Nutritional genomics focuses on the mechanisms that underlie genetic predispositions to diet-based disease as, over time, individuals may have different risks of developing diseases based on their diet. With access to this information through nutrigenetic testing, individuals at risk can have a better understanding of their genetics and the effects of nutrients that they consume $^{(3-8)}$. To avert the development of chronic illness, individuals at risk may take preventive health measures, such as modifying their lifestyle, including their diet.

The dominant delivery model for nutritional genomic services has been through companies, operating primarily in the USA, offering direct-to-consumer (DTC) tests via the Internet ${ }^{(9)}$. Most companies offer their service by selling DNA test kits, whereby individuals return a genetic sample (often from a cheek swab or saliva sample) by mail for analysis. Results, which may include nutritional advice, are generally shared directly with the purchaser of the test.

One of the first companies to offer such testing, the now defunct Sciona Ltd, began to offer personalised dietetic advice based on a genetic test and a lifestyle questionnaire in 2001, first in the UK, and subsequently in the $\mathrm{USA}^{(10)}$. Since that time, numerous advancements in the science have been made and the number of companies offering nutrigenetic testing has grown to over thirty ${ }^{(11-13)}$. Objections to a DTC delivery model have also been growing, including uneasiness that companies are making questionable health claims about tests where validity and utility are not yet well established $^{(14-18)}$. Companies counter with the argument that results are not definitive, but merely indicative of susceptibility to a particular disease ${ }^{(19)}$.

Many of those opposed to DTC testing believe that such services should be offered in a regulated context where a health care professional can act as an intermediary between firms offering tests and individuals taking tests and interpreting the results. Yet concerns linger that no single profession has a strong claim to expertise in all core competencies required to offer nutrigenetic tests, namely genetics, dietetics and medicine ${ }^{(20)}$.

Given the rapid advances of the science of nutritional genomics as well as the acceleration of commercial applications, it is necessary to consider how these developments will affect health care professionals and ultimately the public. For this reason, the authors sought, in collaboration with the Public Health Agency of Canada, to understand health care professionals' knowledge of nutritional genomics and assess 
their perception of the risks and potential benefits that DTC nutrigenetic testing entails.

\section{Experimental methods}

This qualitative study reports results based on focus group discussions. The focus group method creates a context in which a topic can be explored in depth with the assistance of a professionally trained and prepared moderator. Knowledge about the topic of the focus group need not be presumed; often the point of focus groups is to presume little or no knowledge to gauge participants' understanding of, interest and perceived stake in a topic. Accordingly, architects of focus groups use information drawn from literature reviews or other contextual knowledge to develop criteria for a judgment sample of participants. Focus groups involve small numbers of participants, and are not intended to be representative of a larger population. Methods such as phone polling or mail surveys are suitable for studies where the study group needs to be of sufficient size to represent a larger population. These methods trade depth for scope because the questions are fixed, there is no trained and prepared moderator present to follow-up on topics, and because there is a lack of dialogue that reveals subtleties about the topic. Focus groups are a preferred method used by social scientists to explore a topic in depth, such as the introduction of new science and technology, where an understanding of the core issues has yet to be developed. Focus groups have few participants to encourage good group dynamics, and they are time consuming and expensive to run, but their benefit is that they reveal depth and nuance about a topic not achievable by other methods.

In November 2007, four focus group discussions were held in two large Canadian cities (Vancouver and Toronto) (Table 1) with the five main professional groups forming a judgment sample of health care professionals most likely to be engaged by the public on nutritional genomics without a referral. These groups are professionally accredited (within Canada) physicians ( $n$ 5), pharmacists ( $n$ 6), dietitians ( $n$ 4), naturopaths ( $n$ 9) and a nutritionist ( $n$ 1). Physicians and pharmacists were paired, while dietitians, naturopaths and the nutritionist were grouped separately. The grouping rationale is twofold. On the one hand, Canadian health care as dominated by physicians and pharmacists is focused on treatment, whereas dietitians, naturopaths and nutritionists position themselves as offering treatment but also as focused on prevention. Differences in approach to care stem from professional education and training, and are also importantly reflected in how different services are offered to the public. Physicians and pharmacists are mainly in private practice offering government-reimbursable services in Canada, whereas dietitians, naturopaths and nutritionists are similarly private but are not reimbursable through public sources. Ingrained attitudes toward the role and scope of health care practice in Canada

Table 1. Focus group location

\begin{tabular}{lll}
\hline & $\begin{array}{c}\text { Dietitians/naturopaths/ } \\
\text { nutritionists }\end{array}$ & Physicians/pharmacists \\
\hline Toronto & One focus group & One focus group \\
Vancouver & One focus group & One focus group \\
\hline
\end{tabular}

persist between these groups. Participants represented diverse health care settings, including acute and long-term care, private and community/public health care settings. Focus groups were $2 \mathrm{~h}$ in length and comprised of five to seven individuals each. To ensure consistency between the several focus groups, all focus groups were moderated by one of two professional moderators of Phoenix Strategic Perspective Inc. using the same moderator guide developed by the research group ${ }^{(21,22)}$

Before questioning, all respondents were given a brief explanation of the term nutritional genomics to establish a common starting point. It was described as 'a new, developing science that studies the way our genetic make-up affects how our bodies respond to what we eat and drink, where testing is often done by taking a sample of saliva, examining people's genetic make-up and then providing them with nutrition and diet-related information - a kind of personalized nutrition plan - to potentially help them improve their health and reduce their risk of certain diseases'.

The present study was conducted according to the guidelines laid down in the Declaration of Helsinki and all procedures involving human subjects were approved by the University of Ottawa Research Ethics Board. Written informed consent was obtained from all subjects.

Data analysis was performed on the basis of a grounded theory methodology ${ }^{(21,23)}$. Transcripts were read and coded, first by identifying segments of text that relate to a theme (open coding), then by collapsing codes into categories (axial coding), and finally, into broad themes (selective coding). The codes were linked electronically using NVivo (version 6; QSR International, version 6, Doncaster, Vic, Australia), a qualitative software program that aids in the management, sorting and accessing of textual data. With the increasing levels of abstraction during the analysis process, themes begin to emerge; however, findings constantly remain grounded in the experiences of the participants ${ }^{(23,24)}$. All interpretations generated throughout the analysis process created an audit trail such that all codes were recorded and summarised at the end of each transcript. The audit trail served as a record of all the decisions made throughout this process.

\section{Results \\ Concerns over direct-to-consumer testing}

Most health care professionals expressed concerns that individuals who purchase nutrigenetic tests from Internetbased companies and send their genetic samples by mail do so without the assistance of a health care intermediary who can help explain the purpose of the tests and interpret the results.

\section{Naturopath: I don't think the public are able to make the decision - is this what they need or do they need some other basic stuff that a health care practitioner can offer them? \\ Dietitian: Nutrigenetic testing will give participants a false security or false reason to self-medicate.}

Some health care professionals expressed concerns that a DTC delivery model might de-legitimise their professional role. 
Physician: I think [direct-to-consumer] testing could erode all health care workers in the sense that patients are going to just start saying 'We don't even need health care workers. We can go to the Internet. We can get all the information we want on the Internet and diagnose ourselves.' I think it's an erosion of the classic health care model.

\section{Lack of competency}

With the exception of some dietitians, most participants in the focus groups had not heard of nutritional genomics. Therefore, it is not surprising that they would not feel competent in counselling a client seeking help to interpret results from a nutrigenetic test. Instead, health care professionals suggested that they would rely on their existing competencies to assist clients and to address their concerns.

Dietitian: I would first of all say I'm not qualified to really get into nutritional genomics with you but let's look at your lifestyle. Let's look at your history and see what factors are modifiable.

Whether they would consider integrating nutritional genomics in their practice, health care professionals expressed little enthusiasm.

Physician: If a patient asks me 'why do you want to do this', I wouldn't be able to justify its use.

Participants referred to various strategies to access further information regarding nutritional genomics: some would turn to the Internet for guidance, while others called for Health Canada (the federal department of health in Canada) to play a larger role in ensuring trained professionals provided information and guidance. Some health care professionals believed that clinical guidelines would help provide a standardised approach to nutritional genomics counselling.

Physician: The first place to go is the Internet, it's the easiest. There are journal sites or a Medline search engine, which is a peer reviewed service and is up to date.

Physician: I'd like to see Health Canada put together some sort of team of geneticists, pharmacists, physicians, and dietitians that would give us some sort of recommendation about what the state of affairs is in this field. They could then provide updates every once and a while.

There also was little consensus as to the most appropriate group of professionals to whom a patient or client should be referred to for nutritional genomic services. For example, naturopaths and dietitians who possess nutritional expertise but lack it in relation to genetics and genomics would turn specifically to genetic counsellors; others would recommend that patients seek advice from physicians. Pharmacists perceived dietitians to be best equipped to assist clients interested in nutritional genomics.

\section{Genetic scepticism and inevitability}

All health care professionals saw a role for genetics in health care, especially in the future. But with respect to the current delivery of nutrigenetic tests, most health care professionals had concerns. They were generally pessimistic and sceptical toward the current state of knowledge in nutritional genomics, as well as any applications based on it. Various professions tended to have a different basis for their concerns. Naturopaths focused on issues of relevance, of whether genetic tests are necessary in order to support common healthy lifestyle recommendations. Physicians focused on the development of the field, wanting to see more information regarding nutritional genomics before recommending tests and related interventions.

Naturopath: Currently there's not really enough known about how genetic expression works in the human genome. We are more or less just guessing about pretty much everything.

Physician: I have no knowledge of nutritional genomics and so my concern is that this is a new and developing science. We have very little knowledge of it. The science is in its infancy and so it's too early to be recommending treatments that are not founded.

While health care professionals spoke of the current state of nutritional genomics with some scepticism, nearly all accepted that this technology would probably have an impact on health care in the future, placing greater emphasis on preventive care.

Physician: Theoretically, [nutritional genomics] is really good stuff. 100 years from now medicine will be totally different. Right now we treat people after they have a disease. Wouldn't it be neat to just find out what people are susceptible to when they're still young and healthy and never let those things ever happen?

Physician: It's a paradigm shift moving towards prevention as opposed to treating acute - after the fact - illness.

Some health care professionals anticipated that nutritional genomics could result in financial savings, as the results of tests could motivate healthier lifestyles.

Naturopath: It might be cheaper in the long run. If you can detect a [predisposition to] cardiovascular disease you could avoid the costs of a triple bypass.

Physicians stated that they currently use family history to assess patients' susceptibility to disease, and they believed that genetic screening would become a more precise measure. Due to the complexity of genomics, they anticipated that the application of this knowledge would take a long time.

Physician: The number one thing is that if you want to sell this as a real science you would really want to actually prevent or treat disease. But we have to understand what it is that turns on and off certain genes. And I don't think we really think it's plausible to understand how everything really works just because you always learn how complex life is.

Some health care professionals recognised the need to adapt to the availability of DTC genetic tests to ensure that they can help clients/patients who have undergone such tests and are seeking professional assistance. 
Physician: Direct-to-consumer genetic tests can't be stopped. The Internet has become too big, there's too much information. You can find someone somewhere in the world who's going to try and sell you something. We can't stop this so we have to just learn to live with it.

\section{Expectations of regulation}

There was a general consensus amongst health care professionals that the DTC delivery model required additional government oversight. Specifically, they believed Health Canada should develop regulations to protect individuals. This sentiment was strongest amongst physicians.

Physician: The role of the government is to protect the patient. The role of Health Canada is to ensure patient privacy and how information is shared. I'd like to see them go to companies and see that they're actually doing something with the samples and not just making up random results. I think that Health Canada should regulate the lab tests and the kit that comes with it.

Several participants also believed that the government had a responsibility in educating health care professionals with respect to nutritional genomics.

Pharmacist: I would like to know my government is taking steps at helping me as a health care provider in understanding and demystifying this whole process.

Physician: Health Canada should create a website where you could ask questions or you could get a list of nutritional genomic companies that have been fraudulent in some way. You could access the website and see whether they're legit or have some difficulties or lawsuits against them.

\section{Discussion}

\section{Concerns about direct-to-consumer genetic testing}

The ability for the public to access DTC genetic testing without a referral from a health care intermediary is worrisome for health care professionals. Reluctance demonstrated here is consistent with health care professionals' apprehension toward other health-related products and services directly available to consumers, such as DTC diagnostic tests (for example, home pregnancy tests or HIV tests) or DTC advertising of prescription drugs and Internet-based pharmacies ${ }^{(25)}$. Whenever the public can circumvent health care professionals to obtain a diagnosis or prescription drugs, there are concerns that individuals will lack the necessary information to make appropriate treatment decisions, risk greater harm or, at a minimum, be wasting time and/or resources on ineffective interventions $^{(11,12,17)}$. Underlying concerns for patient welfare also may indicate participants' uneasiness of losing some professional authority.

Health care professionals' concerns focusing on harm to the patient were also cited frequently in the findings. These concerns may not be new, yet nutrigenetic tests represent a preventive approach to health care where health care professionals do not traditionally operate. Preventive approaches are more nuanced than a more traditionally utilised curative approach having an impact on levels such as patient empowerment to allocation of resources. Prevention exists remote from diagnosis of disease, resulting in long-term adjustments rather than immediate intervention ${ }^{(26)}$. For that reason, nutrigenetic tests may not raise the same need for counselling or level of anxiety as would diagnostic or highly predictive tests $^{(27-29)}$.

Several participants acknowledged that nutritional genomics could help improve the prevention of disease and, consequently, reduce the costs of health care. Nevertheless, they gave these benefits little weight. This may have been due in part to the belief expressed clearly by one participant that successful preventive measures based on nutritional genomics were 'a hundred years away'. Such beliefs may have been supported from the perspective that genetic testing does not yet provide sufficient information to counsel patients/clients on healthier lifestyles. Also, they may have been supported by the notion that genetic testing is not needed to support common healthy lifestyle recommendations: don't smoke, maintain a healthy body weight, eat a balanced diet, and exercise.

Little emphasis by respondents on the potential for nutritional genomics to have on preventive health is a surprising finding, seeing that the notion of prevention is on the upswing and gaining prominence in public health. Recent trends indicate that consumers and patients are seeking greater control with respect to preventive health care measures ${ }^{(6-8)}$ due to increased levels of education ${ }^{(30)}$, greater access to information via the Internet ${ }^{(31,32)}$, higher income levels ${ }^{(33)}$, as well as a trend toward less trust in professional care ${ }^{(34,35)}$. The Canadian government has also indicated interest in preventive care due to long-term cost-saving potential, with this approach receiving considerable attention in the latest two national commissions on health care ${ }^{(36-38)}$. As such, in the future it might be anticipated that nutritional genomics will be seen in an increasingly favourable light by Canadians and their government.

\section{Lack of knowledge impeding calls for a health care professional-mediated delivery model}

Respondents' preference for a health care professionalmediated delivery model is consistent with appeals from some consumer advocates, health policy analysts, and professional associations for all genetic tests to be offered through clinics where professionals hold the requisite expertise to administer the tests, interpret the results and counsel patients ${ }^{(15,39,40)}$. Interestingly, even though health care professionals cited themselves as the appropriate channel for the delivery of nutrigenetic tests, they also indicated a lack of confidence in their ability to do so. A lack of health care professional competency in genetics and genomics is an unsurprising result, having been reported extensively ${ }^{(41-53)}$. Nevertheless, given the continual calls for health care professionals to increase competency in this area and their continual failure to do so, arguments for a health care professionalmediated delivery model is problematic ${ }^{(46,50,54-56)}$

Since the early 1990s, there has been much discussion on how the results from the Human Genome Project will greatly increase the capacity to detect genes leading to disease susceptibility and will transform clinical care ${ }^{(57)}$. So far it would 
appear that the genomic revolution has only reached biomedical researchers and some specialists, but not the majority of clinicians ${ }^{(47,58)}$. In fact, in the USA, the Secretary's Advisory Committee on Genetics, Health, and Society (SACGHS) ${ }^{(59)}$ has cited health care professionals' lack of genetic and genomic competency as one of the significant barriers towards the successful integration of genomic knowledge into society. Recognising this, organisations such as the National Coalition for Health Professional Education in Genetics (NCHPEG) have published a list of core competencies for health care professionals in genetics to better serve their clients/patients ${ }^{(44)}$. If health care professionals are to play a significant role in mediating the delivery of genetic products and services, their competency in genetic and nutrition will have to be addressed.

With respect to scope of practice, the emergence of a new health technology typically results in a 'turf war' amongst and within professions to claim ownership and demonstrate professional status ${ }^{(60-62)}$. How professions, or specialties within them, negotiate 'ownership' over a new test, device or procedure, can determine where it will fit in the health care system or whether it will at all ${ }^{(63)}$. During this period, the intervention may be thoroughly evaluated through health technology assessment (HTA), a process during which health care professionals' competency to use the technology is evaluated ${ }^{(20)}$. In reality, it is likely that, based on the findings of this research, HTA exercises related to genetic products or services would identify the lack of professional competency as a detractor to the integration of such new technologies into publicly funded health care systems.

With that being said, registered dietitians in Canada and the USA have been particularly interested in gaining knowledge and skills associated with delivering nutrigenetic testing. These health care professionals may be well placed to incorporate nutritional genomics into their scope of practice, already on the periphery of the 'traditional' health care model ${ }^{(64)}$ where 'preventive' health measures garner greater focus ${ }^{(65)}$. They also spend considerable efforts in recommending diets that can help individuals avoid developing disease and their training and expertise in nutrition is unmatched by any other health profession $^{(66,67)}$. Despite these advantages, a number of studies focusing on dietitians' competencies have found that they too lack knowledge in genetics and genomics ${ }^{(68,69)}$, indicating a continued barrier towards professional ownership.

\section{Genetic scepticism and inevitability}

The reaction of respondents towards genetics and genomics indicated a paradox of being sceptical, yet believing its incorporation into health care is inevitable. With respect to nutritional genomics, health care professionals indicated doubts as to whether it was 'sound science', a clear deterrent to offering nutritional genomic-based recommendations to patients. Calls for appropriate evidence of clinical validity and useful findings are seen throughout the literature ${ }^{(20,70)}$; these are some of the largest hurdles for genetic testing to overcome. For that reason it is not surprising that health care professionals see that these issues need to be worked out before they are willing to incorporate testing into practice. With that being said, it is also important to recognise that for definitive data to emerge, tests are needed on large samples of individuals who can be monitored through longitudinal studies.

Scepticism as a participant reaction further demonstrates the gap between the research and practice of genomic science ${ }^{(71)}$. A major challenge exists for new genomic technologies to find their way into the clinical mainstream. This challenge will continue until better research translation strategies are established. Until now, it would appear that the market place has met this challenge with more success. The findings of discomfort and unpreparedness amongst health care professionals in relation to genetics and genomics suggest a certain kind of 'genetic fatalism', a belief that they may be 'doomed, because this technology is coming and they are not yet ready'. This sense of resignation does not support health care professionals' claim that nutritional genomics should be brought under their clinical oversight.

\section{Could new regulations meet the challenge?}

To a majority of respondents, the need for greater regulation emerged as another important theme. Whether these regulations concerned nutrigenetic tests in particular, or all DTC genetic tests, was unclear. Also unclear was their current knowledge of the regulatory authority of the Canadian federal government and of the provincial authorities. That being said, great emphasis was placed on the government to protect, inform and educate the Canadian public. For example, the suggestion of the development of educational resources by the government or other public health organisations was said to be a potential strategy to assist consumers of nutrigenetic testing. Another solution discussed might be to provide the public with online resources and real-time access to specialists, including some trained specifically in nutritional genomics ${ }^{(58)}$.

Some commentators have argued for more stringent regulation of DTC genetic testing to ensure that consumer confidence, safety and privacy are protected ${ }^{(72)}$, echoing the comments of the health care professionals who participated in our research. Most pressing, according to many, are regulations to ensure the quality of tests, specifically their analytical and clinical validity as well as their clinical utility ${ }^{(40,73-76)}$.

While further regulation may promote consumer protection, there is some degree of consensus that any further regulatory intervention pertaining to nutrigenetic tests would need to be unique. Genes involved in nutrigenetic tests for disease susceptibility are generally of low penetrance. Accordingly, some argue that they should be subject to less stringent oversight than those genes involved in diagnostic tests where their penetrance is comparatively high ${ }^{(77)}$. In this way, genetic tests could be regulated depending on a different 'risk-based' profile ${ }^{(9,25)}$. A 'responsive' approach to regulation might allow companies who engage in good practices to face a lighter regulatory load. This may motivate companies to adopt high scientific standards and promote honest marketing efforts $^{(25,78)}$. On the other hand, if too high a regulatory burden is placed on innovators, further advancements in the applications derived from genomic knowledge may emerge much more slowly, stifling scientific progress and its translation into useable knowledge.

Further to regulation of the tests themselves, other regulatory mechanisms can help protect consumers, including restrictions regarding claims about health products that 
treat, prevent, or cure diseases ${ }^{(79)}$ and guidance on truth in advertising ${ }^{(80)}$. Notwithstanding these measures, the regulation of Internet-based services can present additional challenges, particularly when provided by companies based outside of Canada $^{(25,81)}$. Indeed, participants were worried that DTC companies may engage in false and misleading marketing claims. This fear is echoed elsewhere in the literature, that consumers may be left with incomplete, unbalanced and complex information, and with few statements related to risks or over-inflated claims of benefits ${ }^{(14,17,82,83)}$. Alternatively, some policy commentators have proposed that genetic tests and companies that offer them should be listed in a registry, along with sufficient information to assist in the evaluation of tests, thereby providing a degree of transparency ${ }^{(84)}$.

\section{Conclusion}

Results from the present study suggest that health care professionals are not yet ready to incorporate nutrigenetic testing into clinical practice. Preventive approaches to health, such as nutritional genomics, are gaining prominence and public interest in them is growing. Health care professionals are opposed to the public accessing this technology via a DTC delivery model, indicating their need to be involved. But the public should not expect to see health care professionals offering these services soon, as their competency in genetics and genomics is lacking.

The gap between research and practice indicates that if health care professionals seek a role in delivering new genomic technologies, they must develop a clearer role in this knowledge translation pathway. Further training and continuing education would be necessary to bring health care professionals' competency to a level of delivering genomics-based health care. Otherwise, claims for health care professional-mediated delivery models using this technology may continue to fail.

Regardless, appropriate risk-based regulation of DTC genetic testing may ease concerns raised by respondents and ensure greater protection for consumers. Most importantly, regulations are needed to ensure greater clinical validity and utility of tests. Regulators must be careful in their position, however, in ensuring they balance the need to protect consumers without introducing too high a regulatory burden on innovators, where applications could be stifled and genomics-based preventive health care efforts impeded.

\section{Acknowledgements}

The institution where the work was performed is the University of Ottawa (Ottawa, ON, Canada).

The authors acknowledge funding support from the Network of Centres of Excellence for Advanced Foods and Materials (AFMNet; http://www.afmnet.ca).

M. W. was the lead author with K. M., N. R., and D. C. providing revisions. D. C. provided supervision. D. C. is the Canada Research Chair in Science and Society.

There is no conflict of interest that should be disclosed.

\section{References}

1. Kaput J \& Rodriguez RL (2004) Nutritional genomics: the next frontier in the postgenomic era. Physiol Genomics 16, 166-177.
2. Müller M \& Kersten S (2003) Nutrigenomics: goals and strategies. Nature Genet Rev 4, 315-322.

3. Afman L \& Muller M (2006) Nutrigenomics: from molecular nutrition to prevention of disease. J Am Diet Assoc 106, 569-576.

4. DeBusk R (2009) Diet-related disease, nutritional genomics, and food and nutrition professionals. J Am Diet Assoc $\mathbf{1 0 9}$ 410-413.

5. El-Sohemy A (2007) Technical Report. Ottawa, ON: Canadian Agri-Food Policy Institute.

6. Massoud M, Ragozin H, Schmid G, et al. (2001) The Future of Nutrition. Palo Alto, CA: Institute for the Future.

7. Cain M \& Schmid G (2003) From Nutrigenomic Science to Personalized Nutrition: The Market in 2010. Palo Alto, CA: Institute for the Future.

8. Oliver D (2005) The Future of Nutrigenomics: From The Lab to the Dining Room. Palo Alto, CA: Institute for the Future.

9. Hogarth S, Javitt G \& Melzer D (2008) The current landscape for direct-to-consumer genetic testing: legal, ethical, and policy issues. Ann Rev Genomics Hum Genet 9, 161-182.

10. Castle D, Cline C, Daar AS, et al. (2006) Nutrients and norms: ethical issues in nutritional genomics. In Discovering the Path to Personalized Nutrition, pp. 419-434 [J Kaput and R Rodriguez, editors]. Hoboken, NJ: John Wiley \& Sons, Inc.

11. Goddard KAB, Robitaille J, Dowling NF, et al. (2008) Healthrelated direct-to-consumer genetic tests: a public health assessment and analysis of practices related to Internet-based tests for risk of thrombosis. Public Health Genomics 12, 92-104.

12. Sterling R (2008) The on-line promotion and sale of nutrigenomic services. Genet Med 10, 784-796.

13. Genetics and Public Policy Center (2008) Direct-to-Consumer Genetic Testing Companies. Washington, DC: Genetics and Public Policy Center.

14. United States Government Accountability Office (2006) Nutrigenetic Testing: Tests Purchased from Four Web Sites Mislead Consumers. Washington, DC: United States Government Accountability Office.

15. American College of Medicine Genetics Board of Directors (2004) ACMG statement on direct-to-consumer genetic testing. Genet Med 6, 60.

16. Geransar R \& Einsiedel E (2008) Evaluating online directto-consumer marketing of genetic tests: informed choices or buyers beware? Genet Test 12, 13-23.

17. Williams-Jones B (2003) Where there's a web, there's a way: commercial genetic testing and the Internet. Comm Genet 6, $46-57$.

18. Kaye J (2008) The regulation of direct-to-consumer genetic tests. Hum Mol Genet 17, R180-R183.

19. Gill R (2009) Business applications of nutrigenomics: an industry perspective. In Nutrition and Genomics: Issues of Ethics, Law, Regulation, pp. 45-61 [D Castle and N Ries, editors]. New York, NY: Elsevier, Inc.

20. Castle D, Cline C, Daar A, et al. (2007) Science, Society, and the Supermarket: The Opportunities and Challenges of Nutrigenomics. Hoboken, NJ: John Wiley \& Sons, Inc.

21. Strauss AL \& Corbin JM (1990) Basics of Qualitative Research: Grounded Theory Procedures and Techniques. Thousand Oaks, CA: Sage Publications.

22. Public Health Agency of Canada (2007) Moderator Guide (appendix). In Exploring How Canadians Understand Nutrigenomics, pp. 1-140. http://epe.lac-bac.gc.ca/100/200/301/ pwgsc-tpsgc/por-ef/public_health_agency_canada/2008/184-07-a/ report.pdf

23. Strauss AL \& Corbin JM (1994) Grounded theory methodology: an overview. In Handbook of Qualitative Research, pp. 273-285 [N Denzin and Y Lincoln, editors]. Thousand Oaks, CA: Sage Publications. 
24. Hesse-Biber SN \& Leavy P (2004) Approaches to Qualitative Research: A Reader on Theory and Practice. New York, NY Oxford University Press.

25. Ries N (2009) Risk-based regulation of direct-to-consumer nutrigenetic tests. In Nutrition and Genomics: Issues of Ethics, Law, Regulation, pp. 85-102 [D Castle and N Ries, editors]. New York, NY: Elsevier, Inc.

26. Lévesque L, Ozdemir V, Gremmen B, et al. (2008) Integrating anticipated nutrigenomics bioscience applications with ethical aspects. OMICS 12, 1-16.

27. Miki Y, Swensen J, Shattuck-Eidens D, et al. (1994) A strong candidate for the breast and ovarian cancer susceptibility gene BRCA1. Science 266, 66-71.

28. Wooster R, Bignell G, Lancaster J, et al. (1995) Identification of the breast cancer susceptibility gene BRCA2. Nature Genet 378, 789-792.

29. Strittmatter WJ, Saunders AM, Schmechel D, et al. (1993) Apolipoprotein E: high-avidity binding to $\beta$-amyloid and increased frequency of type 4 allele in late-onset familial Alzheimer's disease. Proc Natl Acad Sci U S A 90, 1977-1981.

30. Qi V, Phillips SP \& Hopman WM (2006) Determinants of a healthy lifestyle and use of preventive screening in Canada. BMC Public Health 6, 275.

31. Katz JE \& Rice RE (2002) Social Consequences of Internet Use: Access, Involvement, and Interaction. Boston, MA: Massachusetts Institute of Technology Press.

32. Fox S \& Fallows D (2003) Internet Health Resources: health searches and email have become more commonplace, but there is room for improvement in searches and overall Internet access. Washington, DC: Pew Internet \& American Life Project

33. Neuberger J (2000) The educated patient: new challenges for the medical profession. J Intern Med 247, 6-10.

34. Mechanic D (1996) Changing medical organization and the erosion of trust. Millbank $Q \mathbf{7 4}, 171-189$.

35. Mechanic D (1998) The functions and limitations of trust in the provision of medical care. J Health Polit Policy Law 23, 661-686.

36. World Health Organization (2002) Active Ageing: A Policy Framework. Geneva: World Health Organization.

37. Romanow R (2002) Building on Values: The Future of Health Care in Canada. Ottawa, ON: Commission of the Future of Health Care in Canada.

38. Kirby M (2002) The Health of Canadians - The Federal Role. Ottawa, ON: The Standing Senate Committee on Social Affairs, Science and Technology.

39. American Medical Association (2007) Direct-to-Consumer Advertising and Provision of Genetic Testing. Chicago, IL: American Medical Association.

40. Hudson K, Javitt G, Burke W, et al. (2007) ASHG statement on direct-to-consumer genetic testing in the United States. Am J Hum Genet 81, 635-637.

41. Burke S, Stone A, Bedward J, et al. (2006) A neglected part of the curriculum or of limited use? Views on genetics training by non-genetics medical trainees and implications for delivery. Genet Med 8, 109-115.

42. Bottorff JL, Blaine S, Carroll JC, et al. (2005) The educational needs and professional roles of Canadian physicians and nurses regarding genetic testing and adult onset hereditary disease Comm Genet 8, 80-87.

43. Caulfield $\mathrm{T}$ (1999) Gene testing in the biotech century: are physicians ready? CMAJ 161, 1122-1124.

44. National Coalition for Health Professional Education in Genetics (2007) Recommendations of core competencies in genetics essential for all health professionals. Genet Med 3, $155-159$.

45. Emery J \& Hayflick S (2001) The challenge of integrating genetic medicine into primary care. BMJ 322, 1027-1030.
46. Guttmacher A, Jenkins J \& Uhlmann W (2001) Genomic medicine: who will practice it? A call to open arms. Am J Med Genet 106, 216-222.

47. Guttmacher A, Porteous M \& McInerney J (2007) Educating health care professionals about genetics and genomics. Nature Rev Genet 8, 151-157.

48. Harris R, Challen K, Benjamin C, et al. (2006) Genetic education for non-geneticist health professionals. Comm Genet 9, 224-226.

49. Burton H \& Stewart A (2005) Nutrigenomics: report of a workshop hosted by The Nuffield Trust and organised by the Public Health Genetics Unit on 5 February 2004. Cambridge, UK: The Nuffield Trust. http://www.nuffieldtrust.org.uk/ ecomm/files/Nutrigenomics.pdf

50. Robbins R \& Metcalfe S (2004) Integrating genetics as practices of primary care. Soc Sci Med 59, 223-233.

51. Taylor KL \& Chudley AE (2001) Meeting the needs of future physicians: a core curriculum initiative for postgraduate medical education at a Canadian University. Med Educ 35, 973-982.

52. Trinidad SB, Fryer-Edwards K, Crest A, et al. (2008) Educational needs in genetic medicine: primary care perspectives. Comm Genet 11, 160-165.

53. Vural BK, Tomatır AG, Kurban NK, et al. (2009) Nursing students' self-reported knowledge of genetics and genetic education. Public Health Genomics 12, 225-232.

54. Biesecker BB \& Marteau TM (1999) The future of genetic counselling: an international perspective. Nature Genet 22, $133-137$.

55. Juengst ET (1991) The human genome project and bioethics. Kennedy Inst Ethics J 1, 71-74.

56. Mountcastle-Shah E \& Holtzman NA (2000) Primary care physicians' perceptions of barriers to genetic testing and their willingness to participate in research. Am J Med Genet 94, $409-416$.

57. Institute of Medicine (1994) Assessing Genetic Risks: Implications for Health and Social Policy. Washington, DC: National Academy of Sciences.

58. Shappell H (2009) New models for service delivery: Informed Medical Decisions, Inc. In Innovations in Service Delivery in the Age of Genomics: Workshop Summary, pp. 21-23 [E Hammers, editor]. Washington, DC: The National Academies Press, Inc.

59. Secretary's Advisory Committee on Genetics, Health, and Society (2004) Resolution of the Secretary's Advisory Committee on Genetics, Health, and Society on Genetics Education and Training of Health Professionals. Washington, DC: Secretary's Advisory Committee on Genetics, Health, and Society.

60. Barros PP, Pinto CG \& Machado A (1999) A signalling theory of excessive technological adoption. Health Care Manag Sci $\mathbf{2}$, $117-123$.

61. Kevin J, Bozic KJ, Pierce RG, et al. (2004) Health care technology assessment. Basic principles and clinical applications. J Bone Joint Surg 86, 1305-1314.

62. O'Reilly P (2000) Health Care Practitioners: an Ontario Case Study in Policy Making. Toronto, ON: University of Toronto Press.

63. Miller F, Giacomini M \& Ahern C (2008) Contending visions in the evolution of genetic medicine: the case of cancer genetic services in Ontario, Canada. Soc Sci Med 67, $152-160$.

64. Vogel E, DeBusk R \& Ryan-Harshman M (2009) Advancing knowledge translation in nutritional genomics by addressing knowledge, skills and confidence gaps of registered dietitians. In Nutrition and Genomics: Issues of Ethics, Law, Regulation, pp. 161-186 [D Castle and N Ries, editors]. New York, NY: Elsevier, Inc. 
65. DeBusk R, Fogarty C, Ordovas J, et al. (2005) Nutritional genomics in practice: where do we begin? J Am Diet Assoc 105, 589-598.

66. Farrell J (2009) Health care provider capacity in nutrition and genetics - a Canadian case study. In Nutrition and Genomics: Issues of Ethics, Law, Regulation, pp. 139-159 [D Castle and N Ries, editors]. New York, NY: Elsevier, Inc.

67. Collier R (2009) Canadian medical students want more nutrition instruction. CMAJ 181, 133-134.

68. Whelan K, McCarthy S \& Pufulete M (2008) Genetics and diet-gene interactions: involvement, confidence, and knowledge of dietitians. Br J Nutr 99, 23-28.

69. McCarthy S, Pufulete M \& Whelan K (2008) Factors associated with knowledge of genetics and nutritional genomics among dietitians. J Hum Nutr Diet 21, 547-554.

70. Ng PC, Murray SS, Levy S, et al. (2009) An agenda for personalized medicine. Nature 461, 724-726.

71. Burke W, Kuszler P, Starks H, et al. (2008) Translational genomics: seeking a shared vision of benefit. Am J Bioeth 7, 54-56.

72. Javitt $G$ \& Hudson $K$ (2007) The right prescription for personalized medicine. Per Med 4, 115-118.

73. Javitt $G$ (2007) In search of a coherent framework: options for FDA oversight of genetic tests. Food Drug Law J 62, 616-652.

74. Caulfield T, Burgess M, Williams-Jones B, et al. (2001) Providing genetic testing through the private sector. ISUMA Can J Policy Res 2, 72-81.
75. Hudson K \& Javitt G (2006) Federal neglect: regulation of genetic testing. Issues Sci Technol 22, 58-66.

76. Huang A (2008) Who Regulates Genetic Tests?. Washington, DC: Genetics and Public Policy Center.

77. Hogarth S (2009) Regulation of genetic tests: an international comparison. In Nutrition and Genomics: Issues of Ethics, Law, Regulation, pp. 63-83 [D Castle and N Ries, editors]. New York, NY: Elsevier, Inc.

78. Williams-Jones B \& Ozdemir V (2008) Challenges for corporate ethics in marketing genetic tests. J Bus Ethics 77, 33-44.

79. Department of Justice Canada (1985) Food and Drug Act. Ottawa, ON: Department of Justice Canada.

80. Advertising Standards Canada (2009) The Canadian Code of Advertising Standards. Toronto, ON: Advertising Standards Canada.

81. Mykitiuk R (2004) Caveat emptor: direct-to-consumer supply and advertising of genetic testing. Clin Invest Med 27, $23-32$.

82. Gollust SE, Hull SC \& Wilfond BS (2002) Limitations of direct-to-consumer advertising for clinical genetic testing. JAMA 288, $1762-1767$.

83. Bowen DJ, Battuello KM \& Raats M (2005) Marketing genetic tests: empowerment or snake oil? Health Educ Behav 32, 676-685.

84. Katsanis SH, Javitt G \& Hudson K (2008) Public health: a case study of personalized medicine. Science 320, 53-54. 